\title{
Generating Moving Average Trading Rules on the Oil Futures Market with Genetic Algorithms
}

\author{
Lijun Wang, ${ }^{1,2}$ Haizhong An, ${ }^{1,2,3}$ Xiaohua Xia, ${ }^{4}$ Xiaojia Liu, ${ }^{1,2}$ \\ Xiaoqi Sun, ${ }^{1,2}$ and Xuan Huang ${ }^{1,2}$ \\ ${ }^{1}$ School of Humanities and Economic Management, China University of Geosciences, Beijing 100083, China \\ ${ }^{2}$ Key Laboratory of Carrying Capacity Assessment for Resource and Environment, Ministry of Land and Resources, \\ Beijing 100083, China \\ ${ }^{3}$ Lab of Resources and Environmental Management, China University of Geosciences, Beijing 100083, China \\ ${ }^{4}$ Institute of China's Economic Reform and Development, Renmin University of China, Beijing 100872, China
}

Correspondence should be addressed to Haizhong An; ahz369@163.com

Received 19 February 2014; Revised 4 May 2014; Accepted 7 May 2014; Published 26 May 2014

Academic Editor: Wei Chen

Copyright (C) 2014 Lijun Wang et al. This is an open access article distributed under the Creative Commons Attribution License, which permits unrestricted use, distribution, and reproduction in any medium, provided the original work is properly cited.

The crude oil futures market plays a critical role in energy finance. To gain greater investment return, scholars and traders use technical indicators when selecting trading strategies in oil futures market. In this paper, the authors used moving average prices of oil futures with genetic algorithms to generate profitable trading rules. We defined individuals with different combinations of period lengths and calculation methods as moving average trading rules and used genetic algorithms to search for the suitable lengths of moving average periods and the appropriate calculation methods. The authors used daily crude oil prices of NYMEX futures from 1983 to 2013 to evaluate and select moving average rules. We compared the generated trading rules with the buy-and-hold (BH) strategy to determine whether generated moving average trading rules can obtain excess returns in the crude oil futures market. Through 420 experiments, we determine that the generated trading rules help traders make profits when there are obvious price fluctuations. Generated trading rules can realize excess returns when price falls and experiences significant fluctuations, while $\mathrm{BH}$ strategy is better when price increases or is smooth with few fluctuations. The results can help traders choose better strategies in different circumstances.

\section{Introduction}

Energy is vital for economic development. Household activities, industrial production, and infrastructure investments all consume energy directly or indirectly, no matter in developing or developed countries [1]. Issues pertaining to energy trade [2], energy efficiency [3], energy policy [46], energy consumption [7], and energy finance [8] have received more importance in recent years. Crude oil futures market is a crucial part of energy finance within the scope of the global energy market. Traders and researchers employ technical analysis tools to identify gainful trading rules in financial markets. Accordingly, moving average indicators are commonly used in technical analysis to actualize greater returns. This paper attempts to answer whether in real life an investor can use moving average technical trading rules to obtain excess returns through searching for profitable moving average trading rules with genetic algorithms in the crude oil futures market.

Genetic algorithms are widely used in social sciences $[9,10]$, especially in certain complex issues where it is difficult to conduct precise calculations. It is a trend to apply physical or mathematical methods in energy and resource economics [11-16]. Researchers have applied genetic algorithms to the prediction of coal production-environmental pollution [17], the internal selection and market selection behavior in the market [18], the crude oil demand forecast [19], the minimization of fuel costs and gaseous emissions of electric power generation [20], and the Forex trading system [21]. With respect to the financial technical analysis issues, scholars use 
genetic algorithms to search best trading rules and profitable technical indicators when making investment decisions [2225]. Genetic algorithms are combined with other tools such as the agent-based model [26], fuzzy math theory [27], and neural networks [28]. There are also some studies that have used genetic algorithms to forecast the price trends in the financial market $[29,30]$ or the exchange rate of the foreign exchange market [31]. As there are a vast number of technical trading rules and technical indicators available in the crude oil futures market, it is impractical to use ergodic calculations or certain other accurate calculation methods. Therefore, using genetic algorithms is a feasible way to resolve this issue.

Moving average indicators have been widely used in studies of stocks and futures markets [32-37]. Two moving averages of different lengths are compared to forecast the price trends in different markets. Short moving averages are more sensitive to price changes than long ones. If a short moving average price is higher than a long period moving average price, traders will believe the price will rise and take long positions. When the short moving average price falls and crosses with the long one, opposite trading activities will be taken [38]. Allen and Karjalainen (AK) [39] used genetic algorithms to identify technical trading rules in stock markets with daily prices of the S\&P 500. The moving average price was used as one of the many indicators of the technical rules. Other indicators, such as the mean value and maximum value, are also used when making investment decisions. Wang [40] conducted similar research on spot and futures markets using genetic programing, while How [41] applied AK's method to different cap stocks to determine the relevance of size. William, comparing different technical rules and artificial neural network (ANN) rules regarding oil futures market, determined that the ANN is a good tool, thus casting doubt on the efficiency of the oil market [38]. All of these studies combine moving average indicators with other indicators to generate trading rules. However, in this paper, we utilize moving averages to generate trading rules, which may be a simple and efficient approach.

The performance of a moving average trading rule is affected significantly by the period lengths [42]. Therefore, finding optimal lengths of the two periods above is a central issue in technical analysis literature. A variety of lengths have been tried in existing research projects [43-48]. In the existing research, most of moving average rules use fixed moving average period lengths and single moving average calculation method. However, it is better to use variable lengths for different investment periods $[49,50]$ and there are different types of moving average calculation method that can be used in technical analysis.

In this paper, considering that the optimal length of the moving average periods and the best calculation method may vary from one occasion to another we use genetic algorithms to determine the suitable length of the moving average period and the appropriate method. Six moving average calculation methods are considered in this paper and genetic algorithms can help us find out the best method and appropriate period lengths for different circumstances. Accordingly, we are able to present the most suitable moving average trading rules for traders in the crude oil futures market.

\section{Data and Method}

2.1. Data. We use the daily prices of the crude oil future contract 1 for the period 1983 to 2013 from the New York Mercantile Exchange (Data Source: http://www.eia.gov/ dnav/pet/pet_pri_fut_s1_d.htm). We select 20 groups of sample data, each containing 1000 daily prices. In the 1000 daily prices, a 500-day price series is used to train trading rules in every generation. The following 200 prices are used to select the best generated trading rule from all generations, and the last 300 daily prices are used to determine whether the generated rule can acquire excess returns. The first group begins in 1985, the last group ends in 2013, and each 1000day price series with a step of 300 is selected. We must also include 500 more daily prices before each sample series to calculate the moving prices for the sample period. Thus, every independent experiment requires a 1500 -day price series. The data we use are presented in Figure 1.

2.2. Method. Moving average trading rules facilitate decision-making for traders by comparing two moving averages of different periods. In this way, traders can predict the price trend by analyzing the volatility of the moving average prices. There are six moving average indictors usually used in technical analysis: simple moving average (SMA), weighted moving average (WMA), exponential moving average (EMA), adaptive moving average (AMA), typical price moving average (TPMA), and triangular moving average (TMA). The calculation methods of moving average indicators are presented in Table 1.

To use a moving average trading rule in the oil futures market, at least three parameters must be set to establish a trading strategy. These parameters include the lengths of two moving average periods and the choice of the moving average method from the above six types. Other researchers have used different lengths of sample periods in their studies. In this paper, we use genetic algorithms to determine appropriate lengths of the moving average period. According to existing literature, the long period is generally between 20 and 200 days (very few studies use periods longer than 200 days) $[38,39]$, and the short period is generally no longer than 60 days.

If the long average price is lower than the short average price, a trader will take a long position. It follows that in opposite situations, opposite strategies will be adopted. Noting the price volatility in the futures market, taking a long position when the short average price exceeds the long average price by at least one standard deviation in the short period may be a good rule. Conversely, taking a short position may also be a good rule. Therefore, we designed the two rules in our initial trading rules. The detailed calculation methods of the six moving averages are presented in Figure 2.

A 17-binary string is used to represent a trading rule in which a seven-binary substring represents $(M-N)(M$ is the long period length and $N$ is the short period length); a six-binary substring is $N$ ( $N$ belongs to the range of 1 to 64); a three-binary substring represents the calculation method of average prices. In this paper, the range of $M$ to $N$ is 5 to 132 . The last binary determines whether to 
TABLE 1: Details of the six moving average indicators.

\begin{tabular}{|c|c|}
\hline Indicator & Calculation method ( $p$ denotes price) \\
\hline SMA & $\operatorname{SMA}(k)=\frac{1}{n} \sum_{i=0}^{n-1} p_{k-i}$ \\
\hline WMA & $\operatorname{WMA}(k)=\frac{\sum_{i=0}^{n-1}(n-i) p_{k-i}}{\sum_{i=0}^{n-1}(n-i)}$ \\
\hline EMA & $\begin{array}{l}\operatorname{EMA}(k)=\operatorname{EMA}(k-1)+\operatorname{SC}\left(p_{k}-\operatorname{EMA}(k-1)\right) \\
\text { where } \mathrm{SC}=\frac{2}{(1+n)}\end{array}$ \\
\hline \multirow[t]{2}{*}{ AMA } & $\begin{array}{l}\operatorname{AMA}(k)=\operatorname{AMA}(k-1)+\operatorname{SSC}_{k}^{2}\left(p_{k}-\operatorname{AMA}(k-1)\right) \\
\text { where } \operatorname{SSC}_{k}=\mathrm{ER}_{k}(\text { fastSC }- \text { slowSC })+\text { slowSC, } \\
\text { fastSC }=\frac{2}{(1+2)}, \quad \text { slowSC }=\frac{2}{(1+30)}\end{array}$ \\
\hline & $\mathrm{ER}_{k}=\frac{\left|p_{k}-p_{k-n}\right|}{\sum_{i=k-n+1}^{k}\left|p_{i}-p_{i-1}\right|}$ \\
\hline TPMA & $\begin{array}{l}\operatorname{TPMA}(k)=\frac{(\text { high }+ \text { low }+ \text { close })}{3} \\
\text { where high }=\max \left(p_{m}, p_{m-1}, \ldots, p_{m-n+1}\right), \text { low }=\min \left(p_{m}, p_{m-1}, \ldots, p_{m-n+1}\right), \text { close }=p_{m} .\end{array}$ \\
\hline TMA & $\operatorname{TMA}(k)=\frac{1}{n} \sum_{i=0}^{n-1} \operatorname{SAM}(k-i)$ \\
\hline
\end{tabular}

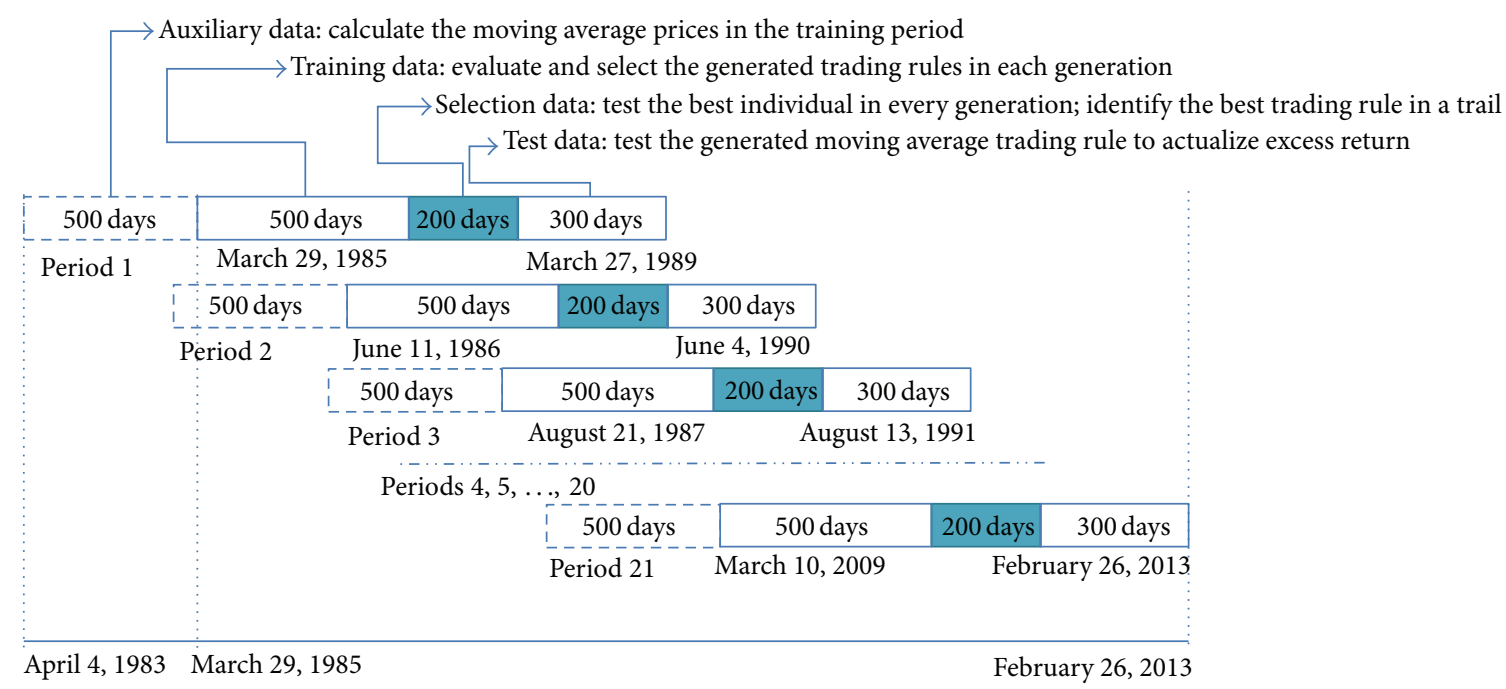

FIGURE 1: Data selection.

change trading strategies only when there is more than one standard deviation difference between two moving average prices. The structure of trading rules is presented in Figure 2. The fitness of a trading rule is calculated according to the profit it can make in the crude oil futures market. To compare generated trading rules with the $\mathrm{BH}$ (buy-and-hold, taking the long position throughout the period) strategy, the profit of a generated rule is the excess return rate that exceeds the $\mathrm{BH}$ strategy.

The calculation method of the return rate references AK's method. The difference is that we allow a trader to hold a position for a long time, and we do not calculate the return every day. Consider

$$
\begin{gathered}
\mathrm{Ra}=\mathrm{Ral}+\mathrm{Ras}+\mathrm{Rf}-\mathrm{Rbh} \\
\mathrm{Ral}=\frac{\sum_{i=1}^{n}\left(\left(P_{\text {out }}-P_{\text {in }}\right) / P_{\text {in }} *(1-c) /(1+c)\right)}{\mathrm{Rm}} \\
\mathrm{Ras}=\frac{\sum_{i=1}^{m}\left(\left(P_{\text {out }}-P_{\text {in }}\right) / P_{\text {in }} *(1-c) /(1+c)\right)}{\mathrm{Rm}} \\
\mathrm{Rbh}=\frac{\left(P_{\text {begin }}-P_{\text {end }}\right)}{P_{\text {begin }}} * \frac{(1-c) /(1+c)}{\mathrm{Rm}} .
\end{gathered}
$$

$\mathrm{Ra}$ is the excess return rate of a long position strategy, that is, the sum of the return of the long position and short 


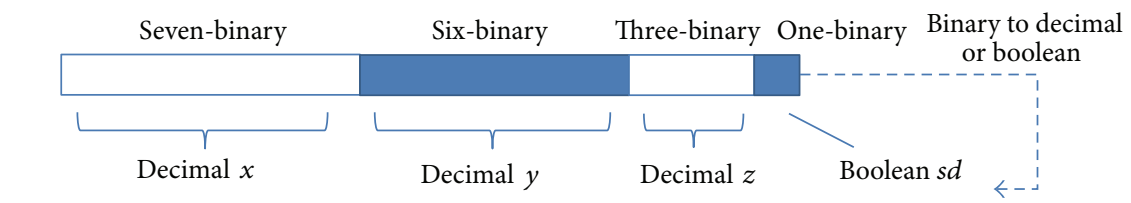

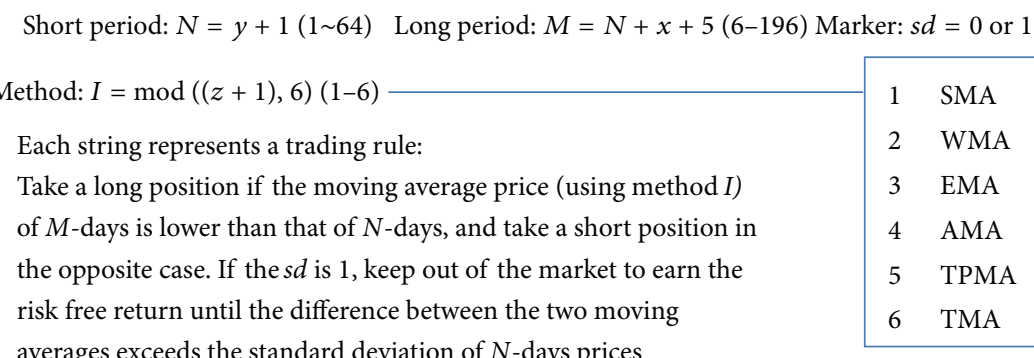

FIGURE 2: Structure of trading rules.

position. Rf is the risk free return when out of market, and $\mathrm{Rbh}$ is the return rate of the $\mathrm{BH}$ strategy in the sample period. $\mathrm{Rm}$ is the margin ratio of the futures market. The parameter $c$ denotes the one-way transaction cost rate. $P_{\text {in }}$ and $P_{\text {out }}$ represent the opening price and closing price of a position (long or short), respectively. $P_{\text {begin }}$ is the price of the first day in a whole period and $P_{\text {end }}$ is the price of the last day. As we ignore the amount of change in the everyday margin and the deadline of the contract, a trader can maintain his strategy by taking new positions when a contract nears its closing date.

The fitness value is a number between 0 and 2 calculated through nonlinear conversion according to $\mathrm{Ra}$. The fitness value calculation, selection, crossover, and mutation of individuals are implemented using the GA toolbox of Sheffield in the Matlab platform. In every generation, to avoid the overfitting of training data, the best trading rule in every generation will be tested in a selection sample period (the 200-day price series). Only when the fitness value is higher than the best value in the last generation or when the two values are almost the same $\left(f_{\text {last }}-f_{\text {now }}<0.05\right)$ can the trading rule be marked as the best thus far. In every generation, 90 percent of the population will be selected to form a new generation, while the other 10 percent will be randomly generated. Accordingly, the evolution of individuals using genetic algorithms in a single independent experiment can be summarized as follows.

Step 1 (initialize population). Randomly create an initial population of 20 moving average trading rules.

Step 2 (evaluate individuals). The fitness of every individual is calculated in the evaluation step. The program calculates the moving average prices in two different scales during the training period using the auxiliary data and determines the positions on each trading day. The excess return rate of every individual is then calculated. Finally, the fitness value of each individual is calculated according to the excess return rate.

Step 3 (remember the best trading rule). Select the rule with the highest fitness value and evaluate it for the selection period to obtain its return rate. If it is better than or not inferior to the current best rule, it will be marked as the best trading rule. If its return rate is lower than or less than 0.05 higher than the current rate, we retain the current rule as the best one.

Step 4 (generate new population). Selecting 18 individuals according to their fitness values, the same individual could be selected more than once. Therefore, randomly create 2 additional trading rules. With a probability of 0.7 , perform a recombination operation to generate a new population. Accordingly, all the recombination rules will be mutated with a probability of 0.05 .

\section{Step 5. Return to Step 2 and repeat 50 times.}

Step 6 (test the best trading rule). Test the best trading rule as identified by the above program. This will generate the return rate and indicate whether genetic algorithms can help traders actualize excess returns during this sample period.

\section{Results}

Because, in this paper, we have not considered the amount of assets, we assume the margin ratio to be 0.05 . In fact, as the parameter has no significant effect on our experiment results, the return rate is increased twenty times. With 20 trials in each period, 420 independent experiments are conducted to determine useful moving average trading rules in the crude oil futures market. The prices we used for the 21 periods are shown in Figure 3.

Based on previous studies $[39,40,51]$ and on the decision to select an intermediate value for this study, the transaction cost rate is set at $0.1 \%$ for the 420 experiments. The risk free return rate is $2 \%$, which is based primarily on the short-term treasury bond rate [41].

Of the 420 trials, 226 earn profits. With an average return rate of 1.446, it is concluded that genetic algorithms can facilitate traders to obtain returns in the crude oil futures 
(1)

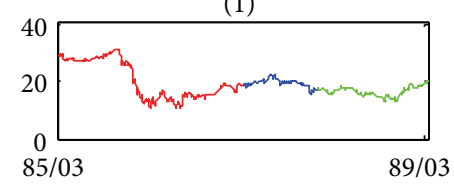

(4)

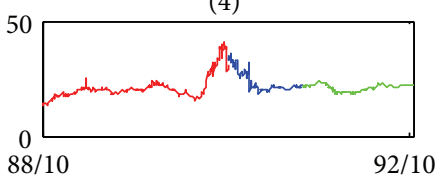

(7)

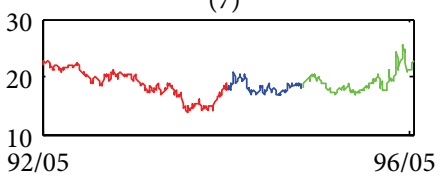

(10)

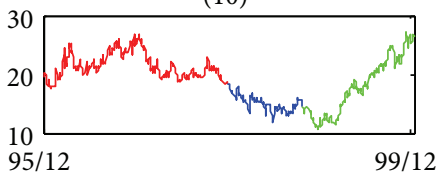

(13)

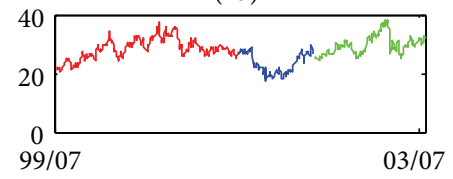

(16)

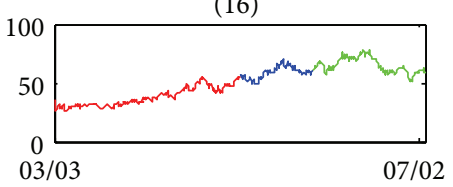

(19)

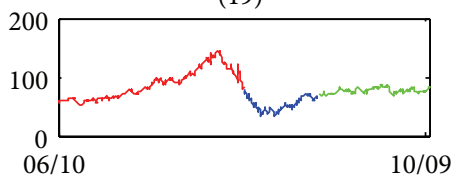

(2)

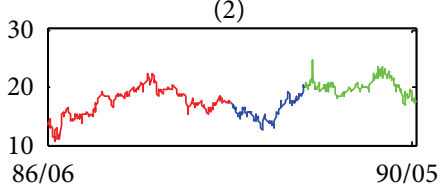

(5)

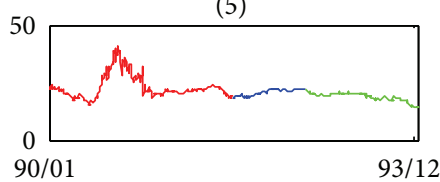

(8)

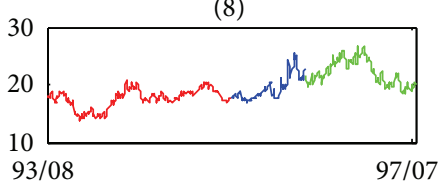

(11)

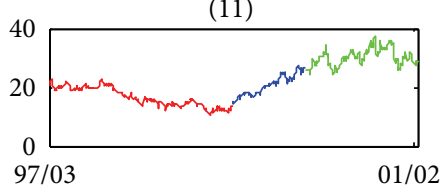

(14)

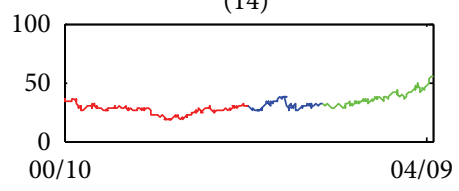

(17)

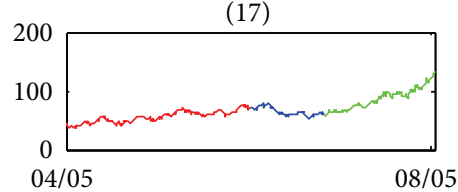

(20)

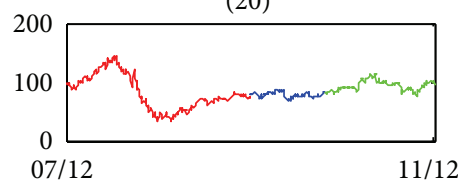

(3)

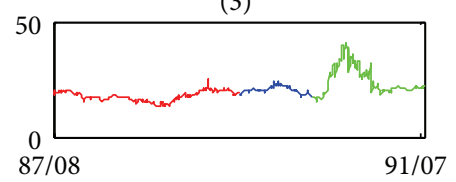

(6)

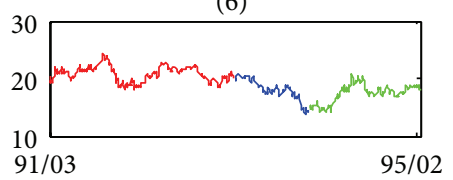

(9)

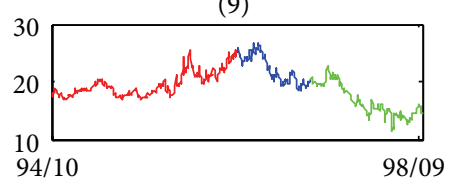

(12)

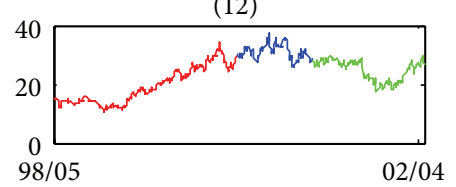

(15)

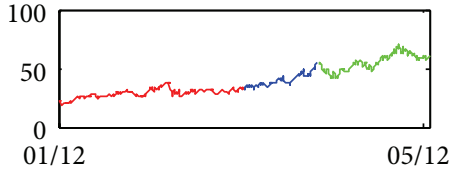

(18)

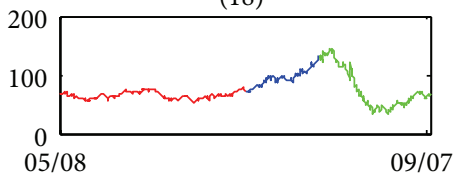

(21)

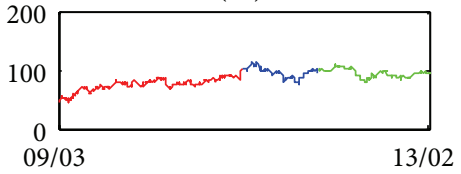

Figure 3: Sample data.

market. However, moving average trading rules identified by genetic algorithms do not result in excess returns as there are only 8 periods in which generated trading rules resulted in traders receiving excess returns. Given that the price of crude oil futures increased many times during the sample period, we further contend that genetic algorithms are helpful in investments.

For a better understanding, we divide the 21 periods into 4 categories according to the results (see the last column of Table 2).

Category 1 (periods 2, 3, and 9). In these periods, generated trading rules not only help traders obtain returns but also help them to realize excess returns. Generated trading rules generate more profits than the $\mathrm{BH}$ strategy in periods 3 and 9. In period 2, the $\mathrm{BH}$ strategy loses money, while the generated trading rules, as determined by the genetic algorithms, result in profits. Thus, the generated trading rules are far superior to the $\mathrm{BH}$ strategy in this period. A common feature of these three periods in Category 1 is that the crude oil prices fell during the test period and experienced significant fluctuations.

Category 2 (periods 5, 8, 12, 16, and 18). Generated moving average trading rules fail to generate profits during these five periods. Even so, the generated rules performed better than the $\mathrm{BH}$ strategy, as they significantly reduced losses. In these periods, prices declined smoothly, experiencing some small fluctuations during the process.

Category 3 (periods $1,6,7,10,11,14,15$, and 17). In these eight sample data periods, genetic algorithms help traders to identify suitable moving average trading rules. However, the traders failed to obtain excess returns. While prices 
TABLE 2: Results of experiment.

\begin{tabular}{|c|c|c|c|c|c|c|}
\hline Period & $Q a$ & $Q$ & Rbh & $\bar{R}$ & $\overline{R a}$ & Classification \\
\hline 1 & 3 & 12 & 3.768 & 0.663 & -3.105 & 3 \\
\hline 2 & 20 & 20 & -2.946 & 2.899 & 5.845 & 1 \\
\hline 3 & 15 & 16 & 5.299 & 7.717 & 2.419 & 1 \\
\hline 4 & 1 & 6 & 0.647 & -0.862 & -1.510 & 4 \\
\hline 5 & 20 & 11 & -7.185 & -0.097 & 7.088 & 2 \\
\hline 6 & 1 & 12 & 4.976 & 0.808 & -4.168 & 3 \\
\hline 7 & 5 & 11 & 5.240 & 1.854 & -3.386 & 3 \\
\hline 8 & 10 & 9 & -1.175 & -0.357 & 0.818 & 2 \\
\hline 9 & 19 & 12 & -5.610 & 0.691 & 6.301 & 1 \\
\hline 10 & 0 & 16 & 16.338 & 6.943 & -9.396 & 3 \\
\hline 11 & 1 & 13 & 2.740 & 0.127 & -2.613 & 3 \\
\hline 12 & 15 & 11 & -1.420 & -0.576 & 0.844 & 2 \\
\hline 13 & 0 & 7 & 4.343 & -2.296 & -6.640 & 4 \\
\hline 14 & 0 & 14 & 14.069 & 3.141 & -10.928 & 3 \\
\hline 15 & 7 & 8 & 2.287 & 0.273 & -2.014 & 3 \\
\hline 16 & 12 & 9 & -0.715 & -0.092 & 0.622 & 2 \\
\hline 17 & 0 & 20 & 26.227 & 21.037 & -5.190 & 3 \\
\hline 18 & 20 & 3 & -9.746 & -4.131 & 5.615 & 2 \\
\hline 19 & 0 & 0 & 3.512 & -6.091 & -9.603 & 4 \\
\hline 20 & 1 & 10 & 2.968 & -0.193 & -3.161 & 4 \\
\hline 21 & 7 & 6 & -0.162 & -1.092 & -0.930 & 4 \\
\hline
\end{tabular}

$\mathrm{Q} a$ is the number of generated trading rules receiving positive excess returns compared with the $\mathrm{BH}$ strategy in the 20 trials. $\mathrm{Q}$ is the number of generated trading rules acquiring returns in the test periods. Rbh is the return rate of the BH strategy. $\bar{R}$ is the average return rate of the 20 trials in each period. $\overline{R a}$ is the average excess return rate of 20 trials in each period.

steadily increase in these periods, there are also some minor fluctuations, which cause the genetic algorithms to be inferior to the $\mathrm{BH}$ strategy in these periods.

Category 4 (periods 4, 13, 19, 20, and 21). Genetic algorithm trading rules demonstrate poor performance in these five periods. In period 21, the $\mathrm{BH}$ strategy yields negative returns. Our genetic trading rules yield more severe losses. The $\mathrm{BH}$ strategy is considered superior to the generated trading rules in the other four periods as the $\mathrm{BH}$ strategy yields some returns. While there are no significant changes in the prices level in these periods, the prices are in volatile states throughout the five periods. Slight price changes with no apparent trends render the generated trading rules helpless in predicting price changes and providing returns.

We use genetic algorithms to search good moving average trading rules for traders in the crude oil market. Table 3 , which shows the average number of $M$ and $N$ for every period, indicates that the value of long period $(M)$ has a close relationship with the volatility of the prices in the sample period. A large $M$ is set in periods with significant fluctuations and a small $M$ is selected for periods in which price is relatively stable.

The distribution of $M$ is shown in Figure 4. The value of Probability is very small and $M$ does not follow normal distribution. The figure presents a typical fat tail characteristic with a kurtosis of 2.36. Compared with normal distribution, there are more values located in the tails of the distribution in our results. Only in half of the 420 experiments, $M$ is between 70 days and 130 days. The values are decentralized and we believe it is more scientific to choose the best lengths of the two periods using a training process that we have used in this paper in actual investment.

Among the six moving average calculation methods, AMA and TMA are used more often than the other four (see Table 4), as more than half of the generated moving average trading rules use AMA or TMA. A small number of generated trading rules use WMA and EMA, while TPMA and SMA, which are easy to calculate, are frequently used in some periods, such as periods $1,2,3,12,19$, and 21 .

The selection of calculation method is associated with the price trends and volatility. Figure 5 shows that TPMA is used 31 times in the 60 independent experiments in periods 2, 3, and 9 (Category 1). Different from the overall proportion, TPMA is the most popular calculation method when price falls during the period and experienced significant fluctuations. AMA is the most popular method in the other three categories. EMA is never used in Categories 1 and 4 . However, it takes a $24 \%$ proportion in Category 2, more than TMA, SMA, TPMA, and WMA. The proportions of TMA and SMA have no significant differences in different categories. In category 4 , prices change with no apparent trends. No one method has obvious advantage over the others.

The results of 20 experiments in the same period indicate high consistency on the value $s d$ (Table 5). When prices fluctuate, such as in periods $1,2,7,8,13,19$, and 20, then not 
TABLE 3: The average value of $M$ and $N$ in each period.

\begin{tabular}{lcccccccccccccccccccccc}
\hline Period & 1 & 2 & 3 & 4 & 5 & 6 & 7 & 8 & 9 & 10 & 11 & 12 & 13 & 14 & 15 & 16 & 17 & 18 & 19 & 20 & 21 & Avg. \\
\hline Avg. $(M)$ & 104 & 108 & 65 & 121 & 101 & 59 & 51 & 55 & 143 & 107 & 140 & 131 & 118 & 81 & 78 & 96 & 160 & 119 & 112 & 101 & 71 & 101 \\
Avg. $(N)$ & 24 & 36 & 15 & 45 & 29 & 29 & 26 & 16 & 47 & 37 & 36 & 43 & 44 & 47 & 22 & 18 & 53 & 24 & 19 & 31 & 40 & 32 \\
\hline
\end{tabular}

TABLE 4: Calculation methods of moving average price in each period.

\begin{tabular}{|c|c|c|c|c|c|c|c|c|c|c|c|c|c|c|c|c|c|c|c|c|c|c|}
\hline \multirow{2}{*}{ Method } & \multicolumn{22}{|c|}{ Period } \\
\hline & 1 & 2 & 3 & 4 & 5 & 6 & 7 & 8 & 9 & 10 & 11 & 12 & 13 & 14 & 15 & 16 & 17 & 18 & 19 & 20 & 21 & Count \\
\hline SMA & 7 & & 4 & & 1 & 4 & 3 & 3 & 7 & & 4 & 10 & 1 & 2 & & & 1 & & 13 & 6 & 3 & 69 \\
\hline WMA & 1 & & & & 1 & 1 & 5 & & 3 & & 2 & & & & & & & 1 & 3 & 6 & & 23 \\
\hline EMA & 1 & & & & & & 4 & 7 & & & & 2 & & & 2 & & & 15 & & & & 31 \\
\hline AMA & 1 & 1 & & 20 & 15 & 14 & 8 & 8 & 2 & 9 & & 4 & & 18 & 16 & 18 & & 2 & & 1 & 8 & 145 \\
\hline TPMA & 8 & 19 & 12 & & & & & 2 & & & 3 & 2 & 6 & & 2 & & & 1 & 3 & & 9 & 67 \\
\hline TMA & 2 & & 4 & & 3 & 1 & & & 8 & 11 & 11 & 2 & 13 & & & 2 & 19 & 1 & 1 & 7 & & 85 \\
\hline
\end{tabular}

opening positions until one average price exceeds another by at least one standard deviation is the best option. When the price is relatively stable, an investment decision should be made immediately as long as the two moving averages cross.

\section{Discussion}

This paper attempts to generate moving average trading rules in the oil futures market using genetic algorithms. Different from other studies, we use only moving averages as technical indicators to identify useful moving average trading rules, without any other complex technical analysis tools or indicators. Moving average trading rules are easy for traders to operate, and they are straightforward regardless of the situation. To identify the best trading rules in the crude oil futures market, we use genetic algorithms to select all the parameters in the moving average trading rules dynamically rather than doing so in a fixed manner.

According to our genetic calculations, using genetic algorithms to find out the best lengths of the two moving average periods is advocated because the generated lengths differ from each other in different price trends. Static moving average trading rules with fixed period lengths cannot adapt to complex fluctuations of price in different periods. A training process, however, which takes dynamic features of price fluctuations into consideration, can help traders find out the optimal lengths of the two moving periods of a trading rule.

Among the six moving average methods, the AMA and TMA are the most popular among the generated trading rules as these two methods have the ability to adapt to the price trends. The AMA can change the weights of the current price according to the volatility in the last several days. As the TMA is the average of the SMA, it more accurately reflects the price level. However, the selection of best moving average calculation method is affected by price trends. Traders can choose methods more scientifically according to the price trends and fluctuations. Based on our experiment results, TPMA is an optimal choice when price experiences a decline process with significant fluctuations, and generating moving average trading rules are outstanding compared with $\mathrm{BH}$ strategy in these occasions. Although EMA takes a very small proportion in the total 420 experiments, it is also an applicable method other than AMA when price falls smoothly.

For the periods in which the price volatility is apparent, decisions will not be made until the difference between the two averages exceeds the standard deviation of the short sample prices, thereby reducing the transaction risk. However, this method is not suitable for a period in which the price is relatively stable. In these situations, hesitation may sometimes cause traders to miss possible profit opportunities.

As a whole, generated moving average trading rules can help traders make profits in the long term. However, genetic algorithms cannot guarantee access to additional revenue in every period as they are only useful in acquiring excess returns in special situations. The generated moving average trading rules demonstrate outstanding performance when the crude oil futures price falls with significant fluctuations. The $\mathrm{BH}$ strategy will lose on these occasions, while the generated trading rule can help traders foresee a decline in price and reduce losses. Our trading rules also yield positive returns during the fluctuations by the timely changing of positions.

When the price falls smoothly with few fluctuations in the process, generated trading rules can yield excess returns compared to the $\mathrm{BH}$ strategy. Although genetic algorithms cannot help traders receive positive returns during these periods, the algorithms can help traders reduce loss by changing positions with the change of price trends. When the price is stable or rising smoothly, the generated rules may generate returns. However, they cannot generate more returns than the $\mathrm{BH}$ strategy. Limited returns cannot afford the transaction costs. When the price falls, the generated rules may be superior to the $\mathrm{BH}$ strategy. Genetic algorithms can also help traders make profits in the process of price increases with small fluctuations. In these periods, the BH strategy is better than generated trading rules because the transactions in the process generate transaction costs and may miss some profit opportunities. Generated moving average trading rules 
TABLE 5: Numbers of trading rules in which $s d=1$.

\begin{tabular}{ccccccccccccccccccccccc}
\hline Period & 1 & 2 & 3 & 4 & 5 & 6 & 7 & 8 & 9 & 10 & 11 & 12 & 13 & 14 & 15 & 16 & 17 & 18 & 19 & 20 & 21 & Count \\
\hline Count & $\mathbf{1 9}$ & $\mathbf{1 9}$ & $\mathbf{2 0}$ & 0 & 5 & 3 & $\mathbf{1 3}$ & $\mathbf{1 2}$ & 0 & 2 & 0 & 0 & $\mathbf{1 3}$ & 2 & 0 & 2 & 0 & 1 & $\mathbf{2 0}$ & $\mathbf{1 9}$ & 0 & 150 \\
\hline
\end{tabular}

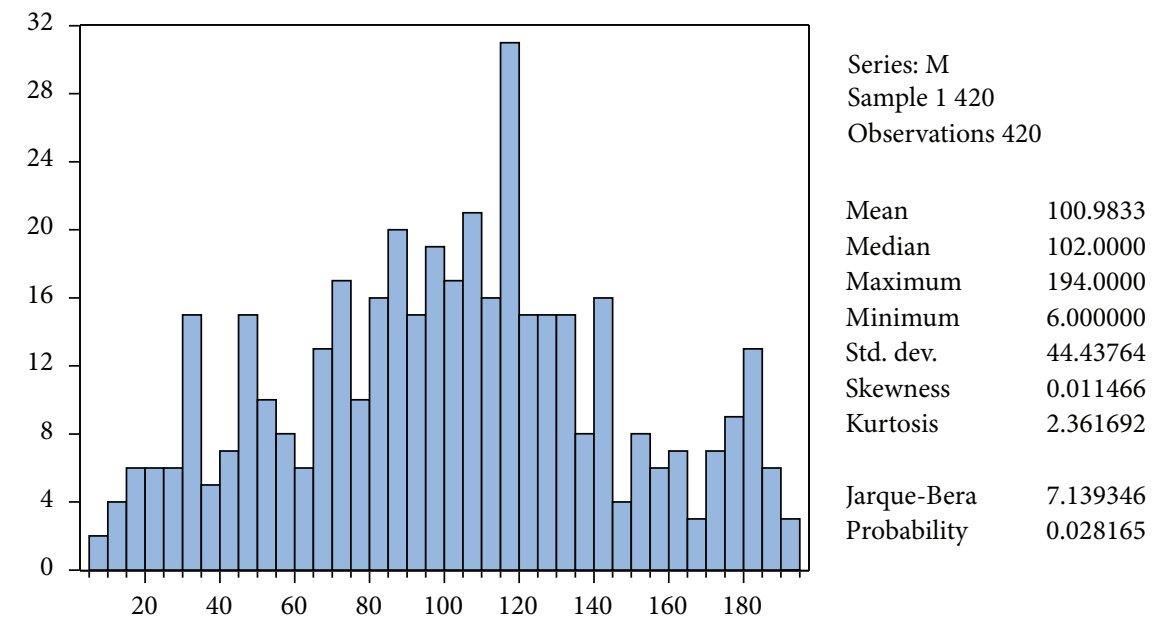

Figure 4: Distribution of $M$.

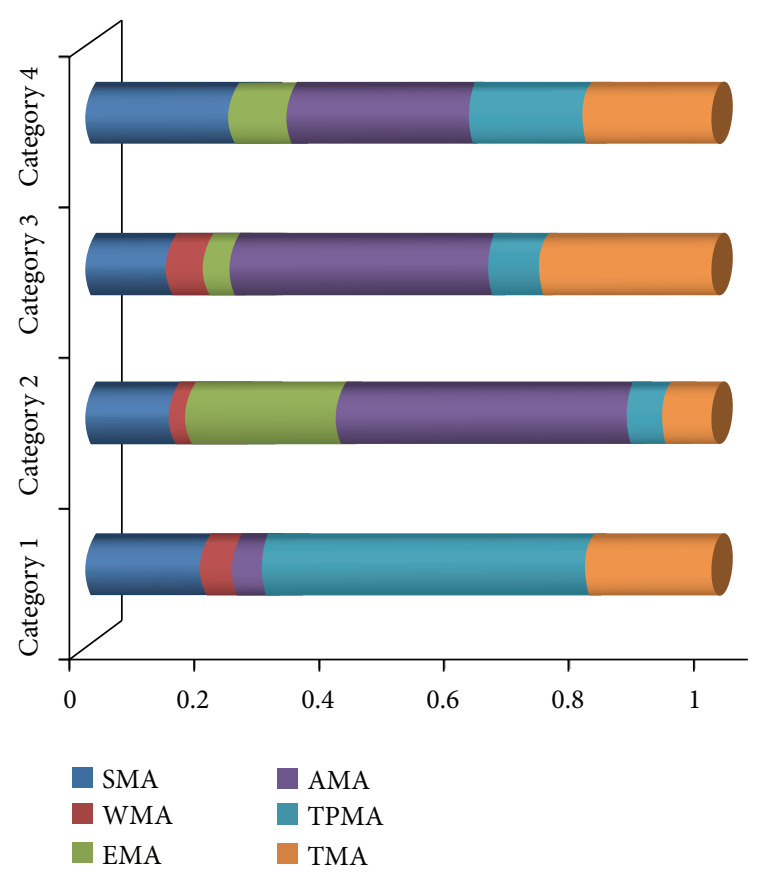

FIGURE 5: Proportions of methods in different categories.

have poor performance if there are no notable trends in the price change. In these periods, moving average indicators cannot find profit opportunities because the volatility is too small. The trends of price changes are delayed by the moving average method. Therefore, when a decision is made, the price trend must also change, and as a result, there is no doubt that the trader will experience deficits.

Using genetic algorithms, moving average trading rules do help traders to gain returns in the actual futures market.
We also identified the best lengths for the two periods with respect to moving average rules and recommend the moving average calculation method for the crude oil futures market. Technical trading rules with only moving average indicators generated by genetic algorithms demonstrate no sufficient advantages compared to the $\mathrm{BH}$ strategy because the overall price increased during the 30-year period. Nevertheless, generated moving trading rules are beneficial for traders under certain circumstances, especially when there are significant changes in prices.

In this paper, we search best trading rules according to the return rate of each one without regard to asset conditions and open interest, which proves to be the greatest limitation of the study. To improve the accuracy of the results, a simulation with actual assets is recommended. Accordingly, we will undertake this endeavor in a subsequent research.

\section{Concluding Remarks}

We conclude that the genetic algorithms identify better technical rules that allow traders to actualize profits from their investments. While we have no evidence to demonstrate that generated trading rules result in greater returns than does the $\mathrm{BH}$ strategy, our conclusion is consistent with the efficient market hypothesis. While generated trading rules facilitate traders in realizing excess returns with respect to their investing activities under specific circumstances, they cannot, at least by using moving average trading rules, ensure more long-term excess returns than the $\mathrm{BH}$ strategy. With respect to the selection of two periods, finding out optimal lengths using genetic algorithms is helpful for making more profits. Of the six moving average indicators, AMA and TMA are the most popular moving average calculation methods for the crude oil futures market in total, while TPMA is an 
outstanding method in some occasion. When the crude oil prices demonstrate notable volatility, a trader is advised to wait until the difference of the two moving averages exceeds the standard deviation of the short period and vice versa.

Based on the above analysis, it is better to use $\mathrm{BH}$ strategy when the price increases or is stable. However, generated moving average trading rules are better than $\mathrm{BH}$ strategy when crude oil futures price decreases. With respect to the moving average calculation method, it is advocated to use TPMA when price falls with significant fluctuations and AMA when price falls smoothly, although TPMA is not a popular method overall. We propose variable moving average trading rules generated by training processes rather than static moving average trading rules in the crude oil futures markets.

\section{Conflict of Interests}

The authors declare that there is no conflict of interests regarding the publication of this paper.

\section{Authors' Contribution}

Model design was done by Haizhong An, Lijun Wang, and Xuan Huang, program development and experiments performance were done by Xiaojia Liu and Lijun Wang, data analysis was done by Haizhong An, Xiaohua Xia, and Xiaoqi Sun, paper composition was done by Lijun Wang, Xiaohua $\mathrm{Xia}$, and Xiaojia Liu, and literature retrieval and manuscript editing were done by Xiaojia Liu, Xuan Huang, and Xiaoqi Sun.

\section{Acknowledgments}

This research was partly supported by the NSFC (China) (Grant no. 71173199) and Humanities and the Social Sciences planning funds project under the Ministry of Education of the PRC (Grant no. 10YJA630001). The authors would like to acknowledge valuable suggestions from Wei Fang, Xiaoliang Jia, and Qier An.

\section{References}

[1] Z. M. Chen and G. Q. Chen, "Demand-driven energy requirement of world economy 2007: a multi-region input-output network simulation," Communications in Nonlinear Science and Numerical Simulation, vol. 18, no. 7, pp. 1757-1774, 2013.

[2] G. Wu, L.-C. Liu, and Y.-M. Wei, “Comparison of China's oil import risk: results based on portfolio theory and a diversification index approach," Energy Policy, vol. 37, no. 9, pp. 3557-3565, 2009.

[3] X. H. Xia, G. T. Huang, G. Q. Chen, B. Zhang, Z. M. Chen, and Q. Yang, "Energy security, efficiency and carbon emission of Chinese industry," Energy Policy, vol. 39, no. 6, pp. 3520-3528, 2011.

[4] X. H. Xia and G. Q. Chen, "Energy abatement in Chinese industry: cost evaluation of regulation strategies and allocation alternatives," Energy Policy, vol. 45, pp. 449-458, 2012.
[5] N. Cui, Y. Lei, and W. Fang, "Design and impact estimation of a reform program of China's tax and fee policies for low-grade oil and gas resources," Petroleum Science, vol. 8, no. 4, pp. 515-526, 2011.

[6] Y. L. Lei, N. Cui, and D. Y. Pan, "Economic and social effects analysis of mineral development in China and policy implications," Resources Policy, vol. 38, pp. 448-457, 2013.

[7] Z. M. Chen and G. Q. Chen, "An overview of energy consumption of the globalized world economy," Energy Policy, vol. 39, no. 10, pp. 5920-5928, 2011.

[8] N. Nomikos and K. Andriosopoulos, "Modelling energy spot prices: empirical evidence from NYMEX," Energy Economics, vol. 34, no. 4, pp. 1153-1169, 2012.

[9] G. B. Ning, Z. J. Zhen, P. Wang, Y. Li, and H. X. Yin, "Economic analysis on value chain of taxi fleet with battery-swapping mode using multiobjective genetic algorithm," Mathematical Problems in Engineering, vol. 2012, Article ID 175912, 15 pages, 2012.

[10] S. Chai, Y. B. Li, J. Wang, and C. Wu, "A genetic algorithm for task scheduling on NoC using FDH cross efficiency," Mathematical Problems in Engineering, vol. 2013, Article ID 708495, 16 pages, 2013.

[11] G. Q. Chen and B. Chen, "Resource analysis of the Chinese society 1980-2002 based on exergy. Part 1: fossil fuels and energy minerals," Energy Policy, vol. 35, no. 4, pp. 2038-2050, 2007.

[12] Z. Chen, G. Chen, X. Xia, and S. Xu, "Global network of embodied water flow by systems input-output simulation," Frontiers of Earth Science, vol. 6, no. 3, pp. 331-344, 2012.

[13] Z. M. Chen and G. Q. Chen, "Embodied carbon dioxide emission at supra-national scale: a coalition analysis for G7, BRIC, and the rest of the world," Energy Policy, vol. 39, no. 5, pp. 2899-2909, 2011.

[14] H. Z. An, X.-Y. Gao, W. Fang, X. Huang, and Y. H. Ding, "The role of fluctuating modes of autocorrelation in crude oil prices," Physica A, vol. 393, pp. 382-390, 2014.

[15] X.-Y. Gao, H.-Z. An, H.-H. Liu, and Y.-H. Ding, "Analysis on the topological properties of the linkage complex network between crude oil future price and spot price," Acta Physica Sinica, vol. 60, no. 6, Article ID 068902, 2011.

[16] X.-Y. Gao, H. Z. An, and W. Fang, "Research on fluctuation of bivariate correlation of time series based on complex networks theory," Acta Physica Sinica, vol. 61, no. 9, Article ID 098902, 2012.

[17] S. Yu and Y.-M. Wei, "Prediction of China's coal productionenvironmental pollution based on a hybrid genetic algorithmsystem dynamics model," Energy Policy, vol. 42, pp. 521-529, 2012.

[18] S. Geisendorf, "Internal selection and market selection in economic genetic algorithms," Journal of Evolutionary Economics, vol. 21, no. 5, pp. 817-841, 2011.

[19] R. Tehrani and F. Khodayar, "A hybrid optimized artificial intelligent model to forecast crude oil using genetic algorithm," African Journal of Business Management, vol. 5, pp. 13130-13135, 2011.

[20] A. M. Elaiw, X. Xia, and A. M. Shehata, "Minimization of fuel costs and gaseous emissions of electric power generation by model predictive control," Mathematical Problems in Engineering, vol. 2013, Article ID 906958, 15 pages, 2013.

[21] L. Mendes, P. Godinho, and J. Dias, "A Forex trading system based on a genetic algorithm," Journal of Heuristics, vol. 18, no. 4, pp. 627-656, 2012. 
[22] M. C. Roberts, "Technical analysis and genetic programming: constructing and testing a commodity portfolio," Journal of Futures Markets, vol. 25, no. 7, pp. 643-660, 2005.

[23] J.-Y. Potvin, P. Soriano, and V. Maxime, "Generating trading rules on the stock markets with genetic programming," Computers and Operations Research, vol. 31, no. 7, pp. 1033-1047, 2004.

[24] A. Esfahanipour and S. Mousavi, "A genetic programming model to generate risk-adjusted technical trading rules in stock markets," Expert Systems with Applications, vol. 38, no. 7, pp. 8438-8445, 2011.

[25] M. A. H. Dempster, T. W. Payne, Y. Romahi, and G. W. P. Thompson, "Computational learning techniques for intraday FX trading using popular technical indicators," IEEE Transactions on Neural Networks, vol. 12, no. 4, pp. 744-754, 2001.

[26] T. Nakashima, Y. Yokota, Y. Shoji, and H. Ishibuchi, "A genetic approach to the design of autonomous agents for futures trading," Artificial Life and Robotics, vol. 11, no. 2, pp. 145-148, 2007.

[27] A. Ghandar, Z. Michalewicz, M. Schmidt, T.-D. To, and R. Zurbrugg, "Computational intelligence for evolving trading rules," IEEE Transactions on Evolutionary Computation, vol. 13, no. 1, pp. 71-86, 2009.

[28] W. L. Tung and C. Quek, "Financial volatility trading using a self-organising neural-fuzzy semantic network and option straddle-based approach," Expert Systems with Applications, vol. 38, no. 5, pp. 4668-4688, 2011.

[29] C.-H. Cheng, T.-L. Chen, and L.-Y. Wei, "A hybrid model based on rough sets theory and genetic algorithms for stock price forecasting," Information Sciences, vol. 180, no. 9, pp. 1610-1629, 2010.

[30] P.-C. Chang, C.-Y. Fan, and J.-L. Lin, "Trend discovery in financial time series data using a case based fuzzy decision tree," Expert Systems with Applications, vol. 38, no. 5, pp. 6070-6080, 2011.

[31] G. A. Vasilakis, K. A. Theofilatos, E. F. Georgopoulos, A. Karathanasopoulos, and S. D. Likothanassis, "A genetic programming approach for EUR/USD exchange rate forecasting and trading," Computational Economics, vol. 42, no. 4, pp. 415431, 2013.

[32] I. A. Boboc and M. C. Dinica, "An algorithm for testing the efficient market hypothesis," PLoS ONE, vol. 8, no. 10, Article ID e78177, 2013.

[33] W. Cheung, K. S. K. Lam, and H. F. Yeung, "Intertemporal profitability and the stability of technical analysis: evidences from the Hong Kong stock exchange," Applied Economics, vol. 43, no. 15, pp. 1945-1963, 2011.

[34] H. Dewachter and M. Lyrio, "The economic value of technical trading rules: a nonparametric utility-based approach," International Journal of Finance and Economics, vol. 10, no. 1, pp. 41-62, 2005.

[35] A. Fernández-Pérez, F. Fernández-Rodríguez, and S. SosvillaRivero, "Exploiting trends in the foreign exchange markets," Applied Economics Letters, vol. 19, no. 6, pp. 591-597, 2012.

[36] M. Metghalchia, J. Marcucci, and Y.-H. Chang, "Are moving average trading rules profitable? Evidence from the European stock markets," Applied Economics, vol. 44, no. 12, pp. 1539-1559, 2012.

[37] C. J. Neely, P. A. Weller, and J. M. Ulrich, "The adaptive markets hypothesis: evidence from the foreign exchange market," Journal of Financial and Quantitative Analysis, vol. 44, no. 2, pp. 467-488, 2009.
[38] W. E. Shambora and R. Rossiter, "Are there exploitable inefficiencies in the futures market for oil?" Energy Economics, vol. 29, no. 1, pp. 18-27, 2007.

[39] F. Allen and R. Karjalainen, "Using genetic algorithms to find technical trading rules," Journal of Financial Economics, vol. 51, no. 2, pp. 245-271, 1999.

[40] J. Wang, "Trading and hedging in S\&P 500 spot and futures markets using genetic programming," Journal of Futures Markets, vol. 20, no. 10, pp. 911-942, 2000.

[41] J. How, M. Ling, and P. Verhoeven, "Does size matter? A genetic programming approach to technical trading," Quantitative Finance, vol. 10, no. 2, pp. 131-140, 2010.

[42] F. Wang, P. L. H. Yu, and D. W. Cheung, "Combining technical trading rules using particle swarm optimization," Expert Systems with Applications, vol. 41, no. 6, pp. 3016-3026, 2014.

[43] J. Andrada-Félix and F. Fernández-Rodríguez, "Improving moving average trading rules with boosting and statistical learning methods," Journal of Forecasting, vol. 27, no. 5, pp. 433449, 2008.

[44] T. T.-L. Chong and W.-K. Ng, “Technical analysis and the London stock exchange: testing the MACD and RSI rules using the FT30", Applied Economics Letters, vol. 15, no. 14, pp. 1111-1114, 2008.

[45] I. Cialenco and A. Protopapadakis, "Do technical trading profits remain in the foreign exchange market? Evidence from 14 currencies," Journal of International Financial Markets, Institutions and Money, vol. 21, no. 2, pp. 176-206, 2011.

[46] A. E. Milionis and E. Papanagiotou, "Decomposing the predictive performance of the moving average trading rule of technical analysis: the contribution of linear and non-linear dependencies in stock returns," Journal of Applied Statistics, vol. 40, no. 11, pp. 2480-2494, 2013.

[47] Y. S. Ni, J. T. Lee, and Y. C. Liao, "Do variable length moving average trading rules matter during a financial crisis period?" Applied Economics Letters, vol. 20, no. 2, pp. 135-141, 2013.

[48] V. Pavlov and S. Hurn, "Testing the profitability of movingaverage rules as a portfolio selection strategy," Pacific-Basin Finance Journal, vol. 20, no. 5, pp. 825-842, 2012.

[49] C. Chiarella, X.-Z. He, and C. Hommes, "A dynamic analysis of moving average rules," Journal of Economic Dynamics \& Control, vol. 30, no. 9-10, pp. 1729-1753, 2006.

[50] X.-Z. He and M. Zheng, "Dynamics of moving average rules in a continuous-time financial market model," Journal of Economic Behavior and Organization, vol. 76, no. 3, pp. 615-634, 2010.

[51] C. Neely, P. Weller, and R. Dittmar, Is Technical Analysis in the Foreign Exchange Market Profitable? A Genetic Programming Approach, Cambridge University Press, 1997. 


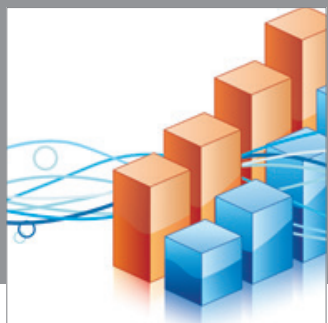

Advances in

Operations Research

mansans

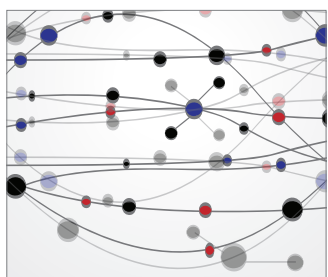

The Scientific World Journal
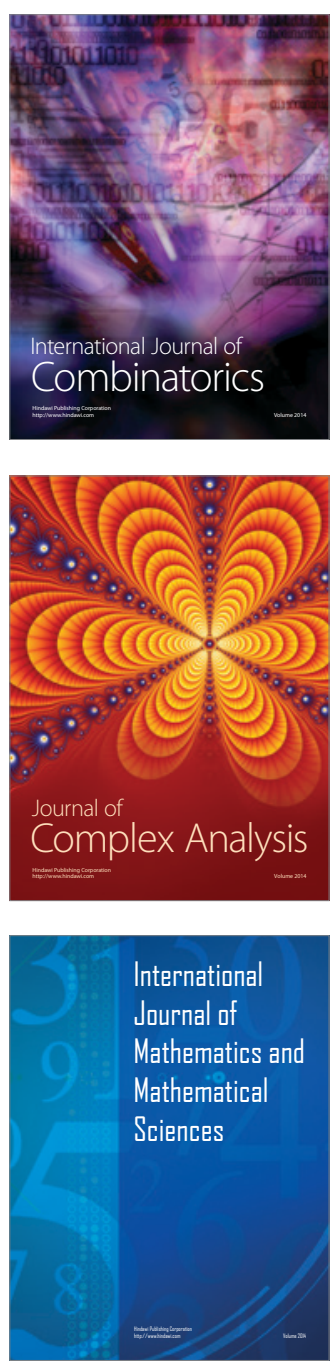
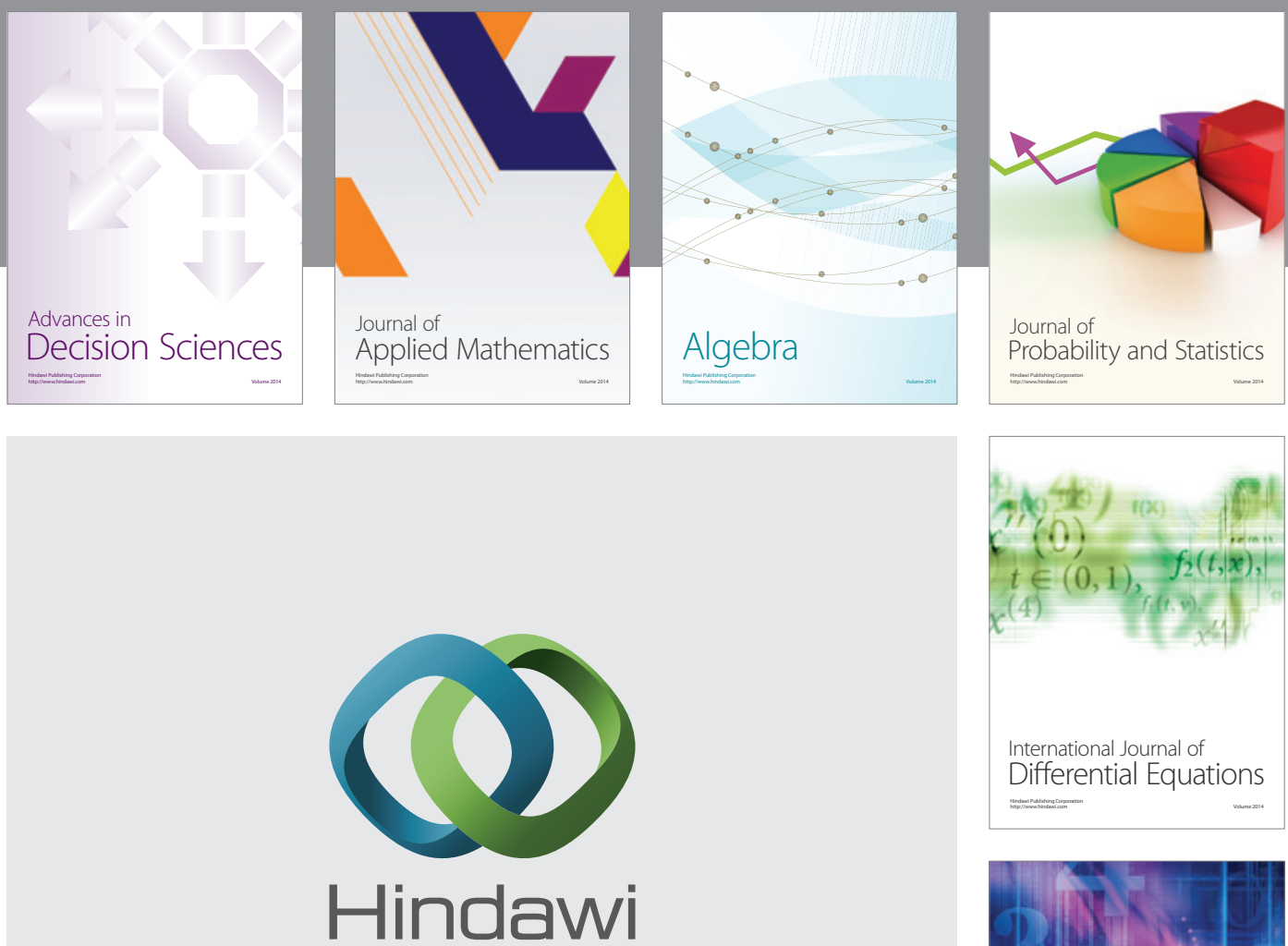

Submit your manuscripts at http://www.hindawi.com
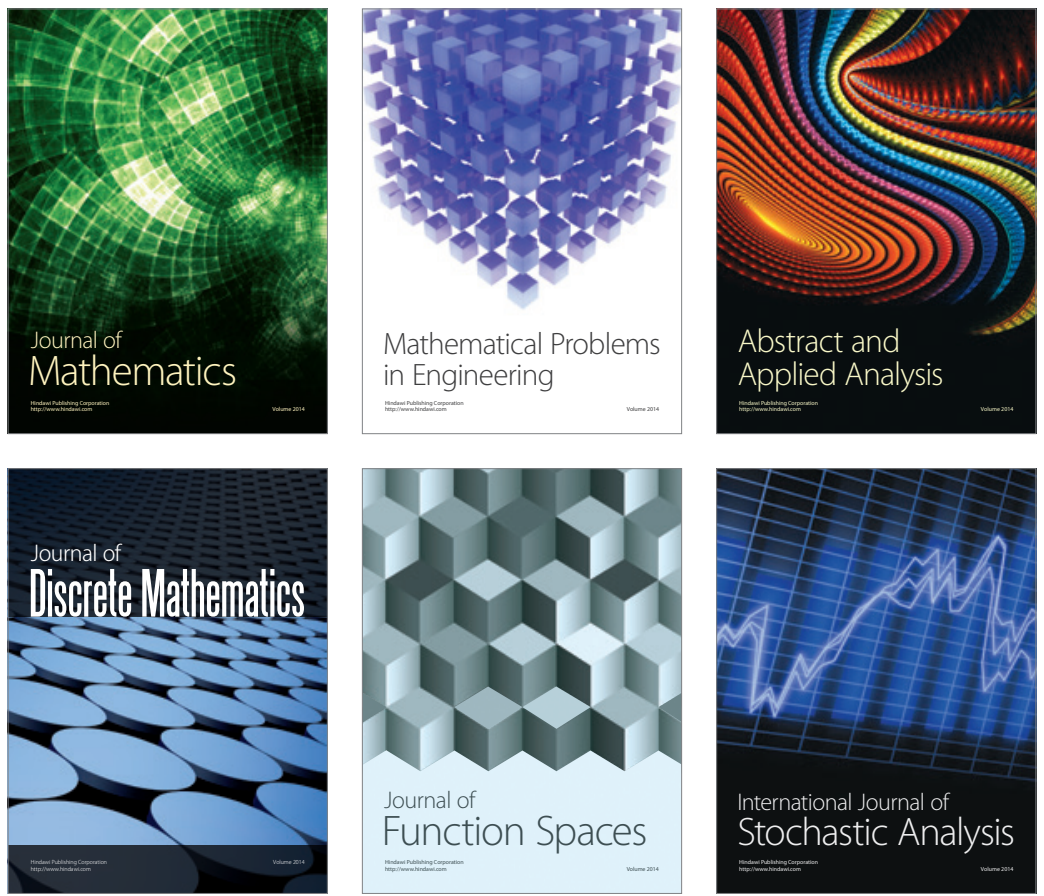

Journal of

Function Spaces

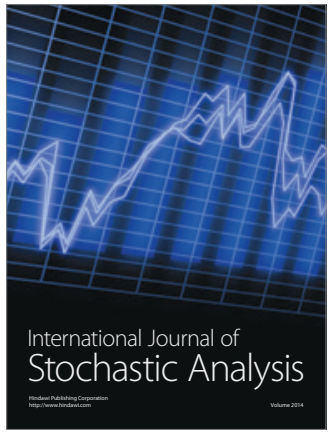

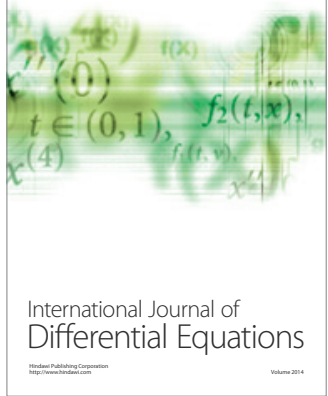
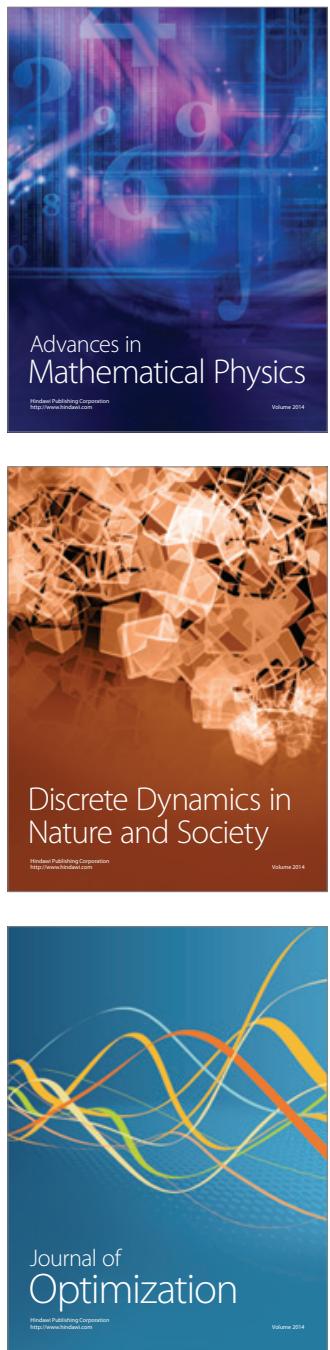